\title{
A Re-Examination of International Portfolio Diversification Based on Evidence from Leveraged Bootstrap Methods
}

\author{
Abdulnasser Hatemi-J* and Eduardo Roca** \\ *Department of Accounting, Finance and Economics, Griffith University, Tel. +61 7555 \\ 28812, Fax: 6175552 8068, E-mail: A.Hatemi-J@Griffith.Edu.Au \\ Dohuk University, Iraqi Kurdistan, and Skovde University, Sweden \\ **Department of Accounting, Finance and Economics, \\ Griffith University, Nathan, Queensland, Australia 4111, Tel. +61 73875 7583, Fax: 617 \\ 3875 7760, Email: E.Roca@griffith.edu.au \\ (Corresponding author)
}

$\underline{\text { Abstract }}$

This article investigates the issue of international portfolio diversification with respect to the three largest financial markets in the world-namely the US, Japan and the UK. In addition to making use of traditional portfolio analysis, we also suggest a procedure to calculate bootstrap correlation coefficients that can take into account the dynamic structure between the markets as measured by bootstrapped causality tests. Weekly data is used. The results from the first approach are supporting international diversification. The bootstrapped causality tests provide additional empirical support for this conclusion since the size of the causal effects is negligible and the bootstrap correlations are similar as the standard ones.

Running title: International Portfolio Diversification

JEL Classification: G11, C32, C30

Keywords: International Portfolio Analysis, Leveraged Bootstrap, Causality 


\section{Introduction}

The existence of the benefits of international portfolio diversification is well-documented since the 1960s (see, for instance, Grubel, 1968; Levy and Sarnat, 1970; Solnik, 1974; Jorion, 1985; Eun and Resnick, 1994; Shawky, et. al., 1997). As provided by portfolio theory, the benefits of diversification spring from the interaction of risk-adjusted returns with correlations (see, Merton, 1972 and Elton and Gruber, 1995). As shown by Elton and Gruber (1995), even if risk-adjusted returns in foreign markets are not higher than those in domestic markets, international diversification leads to higher risk-adjusted returns provided correlations are less than one. The overall evidence is that cross-country correlations are definitely less than one. However, due to the increasing integration and globalisation of markets, there is evidence that correlations have been not only unstable but also increasing over the years (see, for instance, Shawky, et. al, 1997 and Longin and Solnik, 1995). Furthermore, there is also evidence that, depending on whose point of view is taken in terms of investors, foreign returns are actually becoming significantly lower than domestic returns. Thus, with the lower foreign returns and increasing correlations, it is claimed that the gains from international diversification may be decreasing. For instance, Hanna, et. al. (1999) have shown that in the 1990s, from the point of view of an American investor, returns from six foreign developed countries were lower than those in the US and international diversification by American investors into these markets could not result in any diversification gain.

Correlations have been found to be changing over time. In order to understand the stability of these correlations, it is important to know the causal interaction of the markets. For instance, the unconditional correlation between any two markets can be low and therefore provides international diversification benefits but this can disappear over time if the two markets are found to have a stable long-term relationship. Hence, total reliance on unconditional correlations can be misleading. A number of studies have examined the structure of interdependence between stock markets; however, most of these studies have utilised asymptotic methods in the estimation and testing of parameters. It is well-known that these methods lose power when the probability distributions are non-normal. Since it is wellestablished that financial time series are non-normally distributed (see, for example, Chunchachinda, et. al., 1997 for more recent evidence), in contrast with previous studies, we use a bootstrapping approach. It is well-recognised that bootstrapping results in more reliable 
estimates of parameters (see Efron, 1979 and Hacker and Hatemi-J, 2005) and thus our study provides new evidence on the issue of international portfolio diversification.

In this study, we examine the simple case of international portfolio diversification involving the three largest stock markets in the world - US, UK and Japan, from the point of view of American investors over the period 1970 to 2000. We use MSCI weekly price data expressed in US dollars. The MSCI dataset is highly regarded among finance academics and practitioners due to its avoidance of double-listing and its investability as it covers at least $60 \%$ of the capitalisation of each market and includes only highly traded shares. Based on standard portfolio analysis, we first examine whether or not over this period diversification by US investors into the UK and Japanese markets would have been beneficial. We compare the risk-adjusted returns in the US market and that of the tangency portfolio consisting of the US, UK and Japanese markets. We then undertake a causality analysis of the three markets based on a bootstrapping approach. We determine the direction and degree of causality between the markets. The results of this study can always be expanded to accommodate more markets and can also be done from the point of view of investors from the other markets. It can also be replicated on disaggregated scales.

Our study, therefore, differs from previous research on international portfolio diversification in terms of the following:

(a) First, most prior studies verify the existence of international diversification benefits either directly - by showing the position of the investment frontier and identifying the tangency portfolio (see, for example, Haavisto and Hanson, 1992), or indirectly - by simply examining the extent of correlation, interdependence, or integration between markets (see, for instance, Longin and Solnik, 1995 and Roca, 1999). Our study integrates both approaches. In the case of the latter set of studies, there has been no attempt to explicitly relate the causality test results to the size of the international diversification benefits that can be obtained.

(b) Second, although there may be studies, which tried to relate their causality test results to the extent of international diversification benefits (e.g. Darrat and Zhong, 2002, Hatemi-J and Roca, 2004), they do not explicitly provide a clear indication of the degree of causality between markets. Often, these studies simply state the existence and direction of causality. This issue is important as the degree of causality can provide a 
confirmation of the degree of dynamic correlation between markets and therefore, the size of the international diversification benefits. Our study addresses this critical issue.

(c) Finally, since the causality tests that we conduct are based on bootstrapping methods, as stated earlier, our study provide more reliable results in comparison to those of most previous studies that were based on asymptotic methods. As will be discussed later with more details in Section 4 of the study, we utilise the bootstrap test with leveraged adjustments as suggested Hacker and Hatemi-J (2005) and Hatemi-J (2005). We also apply a new information criterion, called the Hatemi-J criterion, for determining the lag length, which has been shown in Hatemi-J (2003) to be superior to existing information criteria, particularly for integrated variables. In addition, we suggest a procedure to calculate bootstrap correlation coefficients that takes into account the causal effects (dynamic structure) between the markets.

Thus, our study is expected to provide significant contribution to the existing literature on international portfolio diversification arising from its use of an integrated framework and more reliable statistical methods.

The rest of the paper is organised as follows. Section 2 presents the literature review while Section 3 outlines the theoretical aspects as well as provides an empirical analysis of international portfolio diversification. Section 4 describes a new method for causality analysis paying special attention to the choice of the optimal lag order. The empirical results for the causality tests are provided in this section. Finally, conclusions are provided in the last section.

\section{Literature Review}

The issue of international diversification has been investigated over a period of more than thirty years now. In the late 1960s, Grubel (1968) examined diversification, from the point of view of a US investor; into ten developed markets during the period 1959 to 1966 based on monthly data and found very significant diversification benefits. Levy and Sarnat (1970) followed this up by examining the same issue but this time over twenty eight markets, which include both developed and emerging markets. In line with the findings of Grubel (1968), the said study also found diversification benefits for the US investor. These benefits were not very significant when diversification was only done into developed markets but were very substantial when emerging markets were included in the diversification. A study by Solnik 
(1973) of diversification into nine European markets, the US and Japan during the period 1966 to 1971 also confirmed the existence of significant benefits. Based on a study of the Nordic stock markets during the period 1970-1988, Haavisto and Hanson (1992) also confirmed earlier results. Eun and Resnick (1994) investigated international diversification from the point of view of US and Japanese investors during the period 1978 to 1989. They found diversification benefits for both investors although these were greater for US investors. The benefits for US investors came mainly from higher returns while those for the Japanese investor came more from a lowering of risk. Another examination of international diversification - this time by Nordic investors into seventeen OECD markets and Hong Kong during the periods 1974-1986 and 1987-1993, was done by Liljeblom, et. al. (1997). The study resulted in the same findings - that of the existence of diversification benefits. There seems therefore to be overwhelming evidence of the presence of international diversification benefits.

There is one study, however, whose findings go against these overwhelming evidence of the presence of international diversification benefits. This is the study by Hanna, et. al. (1999) which found that for a US investor, diversification into the equity markets of Canada, UK, France, Germany, Italy and Japan during the period 1988-1997 would have resulted in no gains at all. This was mainly because the risk-adjusted returns of the US was significantly much higher than those of the other countries during the said period and the correlation between the US and these markets was not low enough to offset these lower foreign market returns. Furthermore, this study found that the number of offsetting market movements between the US and these markets were not favourable enough for diversification.

Furthermore, although there is overwhelming evidence for the existence of international diversification benefits, there are, however, concerns as to whether these international diversification gains have been stable over time. This issue has been primarily dealt with, directly and indirectly, by studies, which examined the correlation, co-movement, interdependence and integration between markets. Some of these studies, particularly the ones on correlations have been undertaken primarily to gain an insight into the size of diversification benefits while others, particularly the ones on financial market integration have been conducted for other objectives such as the understanding of contagion and spill-over effects between markets. Early studies have found that correlations between markets had been relatively low and stable. For instance, the study by Panton, et. al (1976) in its 
investigation covering twelve major stock markets yielded results that showed that stock markets' correlations were stable in the short-term. Kaplanis (1988) examined the correlations of ten markets during the period 1967-82 and found the correlations to be constant across sub-periods. Ratner (1992) also came up with the same results even if the time period examined was different -1987 to 1989. Results of increasing correlations across time, however, were found by Koch and Koch (1991) in their examination of eight stock markets during the periods 1972, 1980 and 1987 and by Von Furstenberg and Jeon (1989) in their analysis of four markets during the period 1986 to 1988 . These results were further supported by the studies of King and Wadwhani (1990), Bertero and Mayer (1990) and King, et. al (1992). Later studies such as those by Erb, et. al. (1994) showed that correlations are unstable - highest during recession and lowest during boom periods. Longin and Solnik (1995) further confirmed that correlations are increasing over time and are highest during times of volatility. A recent study Longin and Solnik (2001) showed that correlations increase during bear markets but not in bull markets. Thus, the overall evidence is that correlations between national stock markets have increased over time but these are still lower than one and than those within the domestic market. All these evidence, however, have been derived based mostly on models that were estimated and tested with asymptotic methods. As pointed out earlier in the introduction, it is well-established that financial time series are nonnormally distributed. Hence, the use of approaches such as bootstrapping methods, which we adopt in this study, provides more robust results in the examination of the issue of international diversification.

\section{International Portfolio Diversification}

Elton and Gruber (1995) have shown that based on Markowitz (1958), it pays to diversify as long as the risk-adjusted returns from the new asset, in this case the foreign market, is not less than a certain proportion of the risk-adjusted return of the domestic market where the proportion is the correlation of the two markets. Using the Sharpe ratio (Sharpe, 1966) as the measure of risk-adjusted return, this is more formally stated below:

$$
\begin{aligned}
\frac{\bar{R}_{F}-r_{R F}}{\sigma_{F}} \geq \frac{\bar{R}_{D}-r_{R F}}{\sigma_{D}} \rho_{F, D}, \text { or } \\
\bar{R}_{F}-r_{R F} \geq\left[\bar{R}_{D}-r_{R D}\right] x\left[\frac{\sigma_{F} \rho_{F, D}}{\sigma_{D}}\right]
\end{aligned}
$$


where:

$r_{R F} \equiv$ risk free rate,

$\rho_{F, D} \equiv$ correlation between returns in foreign and domestic markets in investor's currency,

$\bar{R}_{D} \equiv$ domestic returns (investor's market),

$\bar{R}_{F} \equiv$ returns on foreign investment in investor's currency,

$\sigma_{F} \equiv$ standard deviation of returns in foreign market,

$\sigma_{\mathrm{D}} \equiv$ standard deviation of returns in domestic market.

In the presence of a risk-free asset, the international portfolio diversification gains can be verified through the identification of the tangency portfolio. The risk-adjusted returns of this tangency portfolio of internationally diversified assets can then be compared against the returns on the domestic asset. Note that the tangency portfolio represents the optimal combination of risky assets and is derived irrespective of the investor's utility function following Tobin's (1958) separation theorem. The tangency portfolio can be derived, as follows, by optimising the Sharpe ratio subject to the constraint that the weights equal to 1 :

$$
\begin{aligned}
\operatorname{Max} \delta & \equiv \frac{\overline{\mathrm{R}}_{\mathrm{p}}-r_{R F}}{\sigma_{p}} \\
= & \frac{\sum_{1}^{\mathrm{N}} w_{i}\left(\bar{R}_{i}-r_{R F}\right)}{\sum_{i=1}^{N} \sum_{j=1}^{N} w_{i} w_{j} \sigma_{i j}}
\end{aligned}
$$

Subject to: $\sum_{\mathrm{i}=1}^{\mathrm{N}} w_{i}=1.0$ and $\mathrm{w}_{\mathrm{i}} \geq 0$

where :

$w_{i}=$ proportion of investment in the $i$ th asset,

$\bar{R}_{i}=$ expected return on the $i$ th asset,

$r_{R F}=$ risk - free rate,

$\overline{\mathrm{R}}_{\mathrm{p}}=$ expected return on the portfolio,

$\sigma_{i j}=$ covariance of returns between the $i$ th and $j$ th asssets,

$\sigma_{p}=$ standard deviation of portfolio returns.

Based on the weekly Morgan Stanley Capital International (MSCI) price data for the period 1970-2000, as previously discussed, we calculate the returns in terms of unadjusted and risk- 
adjusted based on the Sharpe ratio, risk of each market in terms of standard deviations, minimum risk-adjusted returns needed for diversification to be beneficial, and the gains from international diversification. We use the ten-year US government bond yield as proxy for the risk-free rate. ${ }^{1}$ The results of these calculations are presented in the upper part of Table 1. The lower part of the Table shows the unconditional contemporaneous correlations between the markets.

\section{Table 1}

Summary of Results of International Portfolio Diversification Analysis

Based on US, UK and Japanese Equity Markets

Weekly Data - 28 January 1970 to November 2000

USD or American Investor Perspective

\begin{tabular}{|c|c|c|c|c|c|}
\hline \multirow[b]{2}{*}{ Market } & \multirow[b]{2}{*}{ Returns } & \multirow[b]{2}{*}{$\begin{array}{l}\text { Standard } \\
\text { Deviation }\end{array}$} & \multicolumn{3}{|c|}{ Minimum } \\
\hline & & & Sharpe Ratio & $\begin{array}{c}\text { Sharpe } \\
\text { Ratio }\end{array}$ & Gains \\
\hline US & $0.18 \%$ & $2.1 \%$ & $3.8 \%$ & $3.8 \%$ & $46.1 \%$ \\
\hline Japan & $0.25 \%$ & $3.0 \%$ & $5.0 \%$ & $1.1 \%$ & \\
\hline UK & $0.20 \%$ & $3.2 \%$ & $3.0 \%$ & $1.7 \%$ & \\
\hline \multicolumn{6}{|c|}{ Tangency- } \\
\hline portfolio & $0.22 \%$ & $2.1 \%$ & $5.6 \%$ & & \\
\hline \multirow[t]{2}{*}{ Weights } & US & Japan & UK & & \\
\hline & $41 \%$ & $51 \%$ & $8 \%$ & & \\
\hline \multicolumn{6}{|c|}{ Correlations } \\
\hline & US & Japan & UK & & \\
\hline US & 1 & $0.294584^{\star \star \star}$ & $0.443166^{\star \star \star}$ & & \\
\hline Japan & $0.294584^{\star \star \star}$ & 1 & $0.325173^{\star \star \star}$ & & \\
\hline UK & $0.443166^{\star \star \star}$ & $0.325173^{\star \star \star}$ & 1 & & \\
\hline
\end{tabular}

Risk-free rate (weekly) $0.1 \%$

*** implies the null hypothesis that the correlation coefficient is equal to 1 can be rejected at the one percent significance level. ${ }^{2}$

\footnotetext{
${ }^{1}$ It is therefore assume that international diversification is being undertaken from a long-term rather than short-term perspective in line with a buy-and-hold strategy.

${ }^{2}$ The null hypothesis of $r=1$, where $\mathrm{r}$ is representing the correlation coefficient, is tested by the following test statistic:$$
t_{n-2}=\frac{r-1}{\sqrt{\frac{1-r^{2}}{n-2}}} \text {. This test statistic is t-distributed with } \mathrm{n}-2 \text { degrees of freedom, where } \mathrm{n} \text { is sample size. }
$$ 
As can be seen in this Table (see Sharpe ratio column), the US has a risk-adjusted return of $3.8 \%$, Japan $5.0 \%$ while the UK has only 3.0\%. Based on these figures, from the point of view of an American investor, it appears that the Japanese market is therefore a good candidate for diversification since it has a higher risk-adjusted return than that of the US market while the UK market is not because it has a lower risk-adjusted return as compared to the US market. However, based on Elton and Gruber (1995) as expressed in Equation 1, the correlations of each market with the US market should be taken into account. Equation 1 states that even if the risk-adjusted return of the foreign market is lower than that of the domestic market, it will still pay to diversify provided the correlation is low enough. This equation provides the minimum risk-adjusted return (in term of the Sharpe ratio) from the foreign market taking into account the correlation that is necessary for international diversification to be beneficial.

The minimum Sharpe ratio required for each market based on Equation 1 is presented in Table 1. For the Japanese market, it is $1.1 \%$. Since it (Japanese market) has a Sharpe ratio of $5.0 \%$, it is therefore an excellent candidate for inclusion into the international portfolio. For the UK market, the minimum Sharpe ratio required is $1.7 \%$. Its present Sharpe ratio is $3.0 \%$ which is below that of the US market. However, it is still way above that of the required minimum. Hence, the UK is also a good candidate for inclusion into the international portfolio.

Thus, diversifying both into the Japanese and UK markets, from an American investor's point of view, can provide diversification benefits. This is confirmed by the tangency portfolio, consisting of the three markets, that is identified on the basis of a weekly risk-free rate of $0.1 \%$ and the assumption that short-sales are not allowed following Elton and Gruber (1995, p. 276). This diversified portfolio, which consists of 51\% investment in the Japanese market, $41 \%$ in the US market and only $8 \%$ in the UK market, results in a risk-adjusted return of $5.6 \%$. This represents a gain of $46.1 \%$ from the risk-adjusted return of $3.8 \%$ if the investment was purely on the US market (no diversification). Figure 1 summarises these results. Thus, for the period 1970-2000, the results from these ex-post analyses indicate that diversification for the US investor to these three markets would have been beneficial. These results are in line with existing overall evidence on international portfolio diversification. 


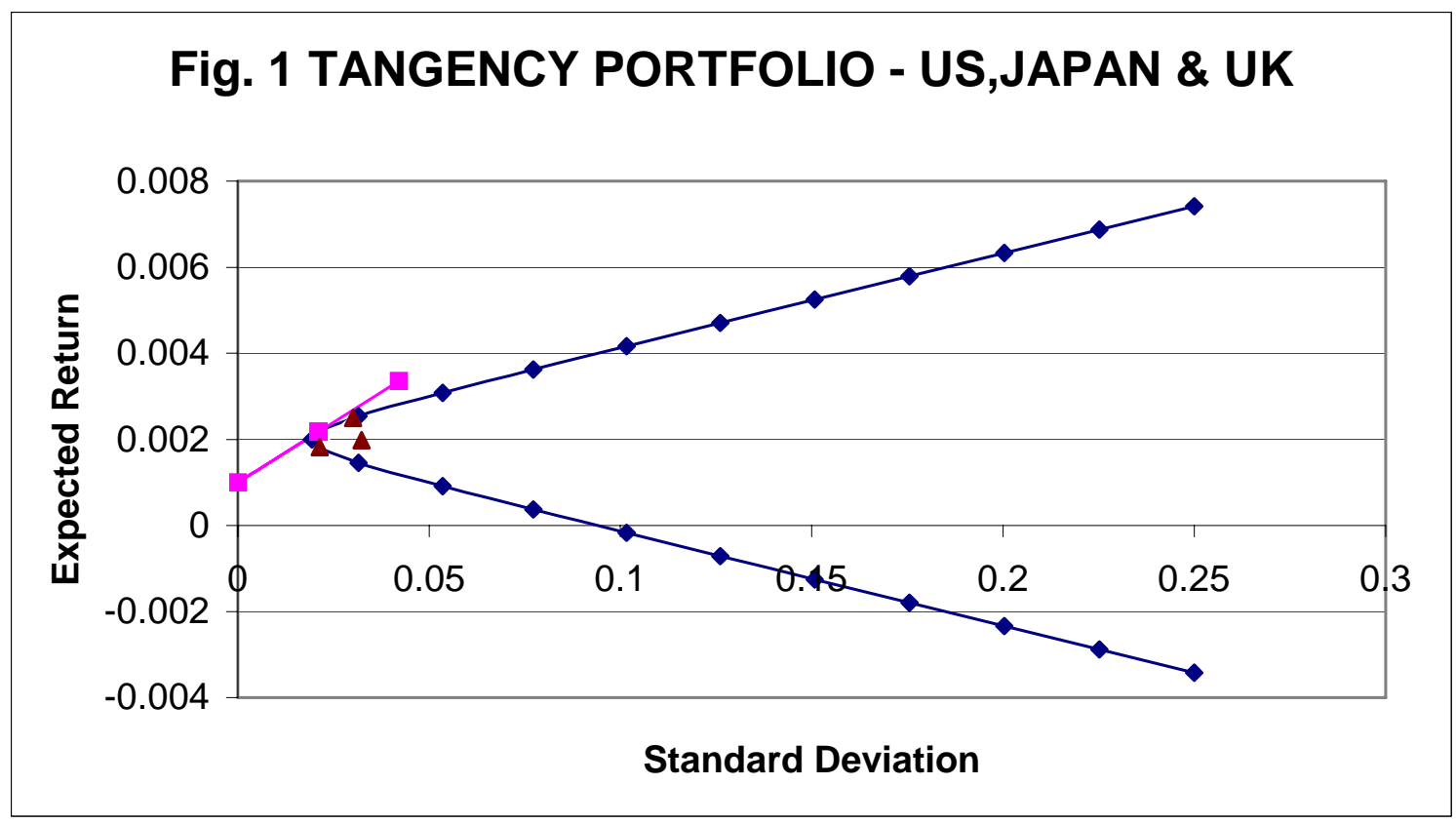

But are these gains, which are anchored on unconditional correlations sustainable over time? Studies by King and Wadhwani (1990), Lee and Kim (1993) and Longin and Solnik (1995) have shown that unconditional correlations among stock markets change positively with market volatility. The results from the bootstrap causality tests and bootstrap correlations presented in the next section can shed light on this. This is because causality tests facilitate a more reliable computation of correlations in view of the changing correlation structure of markets.

\section{Causality Analysis}

Prior to causality analysis, we conduct the augmented Dickey-Fuller and the Phillips-Perron tests for unit roots on the data, i.e. returns ${ }^{3}$ in each country. Results from these tests show that the returns for each country are stationary. ${ }^{4}$

\subsection{The Optimal Lag Order in the VAR Model}

To conduct tests for causality, we apply the following vector autoregressive (VAR) model:

$$
X_{t}=\beta_{0}+\sum_{k=1}^{K} \beta_{k} X_{t-k}+\varepsilon_{t}, \quad t=1, \cdots, T
$$

where $\varepsilon_{t}$ is a $3 \times 1$ vector of error terms that are assumed to be independently identically distributed, $\beta_{k}$ is a matrix of coefficients for $X_{t-k} . X_{t}$ is a $3 \times 1$ vector containing returns for the

\footnotetext{
${ }^{3}$ Based on the first difference of the natural logarithm of prices.

${ }^{4}$ The results for unit roots are not presented here to save space but they are available from the authors.
} 
US, the UK and Japan. One crucial aspect of the VAR model is the choice of the optimal lag order $(K)$ because all inference in the VAR model is based on the chosen lag length. For this end, we make use of the Hatemi-J (2003) information criterion, which is presented below

$$
H J C=\ln \left(\operatorname{det} \widehat{\Omega}_{j}\right)+j\left(\frac{n^{2} \ln T+2 n^{2} \ln (\ln T)}{2 T}\right), \quad j=0, \cdots, K,
$$

where $\ln$ is natural logarithm, $\operatorname{det} \widehat{\Omega}_{j}$ denotes the determinant of the estimated variancecovariance matrix of the error terms in the VAR model for lag order $j, n$ stands for the number of variables and $T$ signifies the number of observations used to estimate the VAR model. Monte Carlo simulation experiments conducted by Hatemi-J $(2003,2006)$ show that this new information criterion performs well, especially for integrated variables.

\subsection{Test for Causality}

In applied research, Granger causality (Granger, 1969) is a well-known concept. The meaning of causality in the Granger sense is based on the idea that the past cannot be caused by the present or future. Hence, if an event takes place before another event, causality can only come about from the first event to the second one. Granger formulated a test statistic to test whether movements in one variable systematically precede movements in another variable. In a regression framework, this means running a regression of one variable on the past values of itself and the past values of any potentially causal variable, and testing the significance of coefficient estimates associated with the potentially causal variable. To test for causal effects we make use of the Wald principle (W), which is based on the unrestricted model. In order to define the test statistic in a compact way, we make use of the following denotations for a sample size $T$ :

$$
\begin{aligned}
& X:=\left(X_{1}, \cdots, X_{T}\right) \quad(n \times T) \text { matrix, } \\
& D:=\left(\beta_{0}, \beta_{1}, \cdots, \beta_{K}\right) \quad(n \times(1+n \times K)) \text { matrix, } \\
&\left.Z_{t}:=\left[\begin{array}{c}
1 \\
X_{t} \\
X_{t-1} \\
\vdots \\
X_{t-K+1}
\end{array}\right] \quad((1+n \times K)) \times 1\right) \text { matrix, for } t=1, \ldots, T, \\
& Z:=\left(Z_{0}, \cdots, Z_{T-1}\right) \quad((1+n \times K) \times T) \text { matrix, and } \\
& \delta:=\left(\varepsilon_{1}, \cdots, \varepsilon_{T}\right) \quad(n \times T) \text { matrix. }
\end{aligned}
$$


By using this notation and assuming that the initial values are fixed, the estimated $\operatorname{VAR}(K)$ model including an estimated constant term $\left(\beta_{0}\right)$ can be written compactly as:

$$
X=\hat{D} Z+\hat{\delta}
$$

We proceed by estimating $\hat{\delta}_{U}$, the $(n \times T)$ matrix of estimated residuals from the unrestricted regression (5). We then calculate the variance-covariance matrix of these residuals as $S_{U}=\frac{\hat{\delta}_{U}{ }^{\prime} \hat{\delta}_{U}}{T}$. Let us define $\hat{B}=\operatorname{vec}(\hat{D})$, where vec denotes the column-stacking operator. The Wald test statistic for testing non-Granger causality of one variable in $X_{t}$ on another variable in $X_{t}$, is then written as

$$
W=(C \hat{B})^{\prime}\left[C\left(\left(Z^{\prime} Z\right)^{-1} \otimes S_{U}\right) C^{\prime}\right]^{-1}(C \hat{B})
$$

where $\otimes$ is the Kronecker product, and $C$ is a $K \times n(1+n \times \mathrm{K})$ indicator matrix to identify which parameters should undertake the restrictions implied by the null hypothesis of no Granger causality. Using this compact notation, the null hypothesis of no Granger causality is defined as

$$
H_{0}: C B=0
$$

The $W$ test statistic is asymptotically $\chi^{2}$ distributed with the number of degrees of freedom equal to $K$, the number of restrictions to be tested. ${ }^{5}$ However, the simulation experiments conducted by Hacker and Hatemi-J (2005) and Hatemi-J (2005) show that the inference based on the $W$ test statistic becomes more precise if bootstrap distributions are used instead of

5 In a system of three variables, as it is in our case, we can use the following $\operatorname{VAR}(K)$ model:

$$
\begin{gathered}
{\left[\begin{array}{l}
X_{1 t} \\
X_{2 t} \\
X_{3 t}
\end{array}\right]=\left[\begin{array}{l}
\beta_{01} \\
\beta_{02} \\
\beta_{03}
\end{array}\right]+\left[\begin{array}{lll}
\beta_{1,11} & \beta_{1,12} & \beta_{1,13} \\
\beta_{1,21} & \beta_{1,22} & \beta_{1,23} \\
\beta_{1,31} & \beta_{1,32} & \beta_{1,33}
\end{array}\right] \times\left[\begin{array}{l}
X_{1 t-1} \\
X_{2 t-1} \\
X_{3 t-1}
\end{array}\right]+\left[\begin{array}{lll}
\beta_{2,11} & \beta_{2,12} & \beta_{2,13} \\
\beta_{2,21} & \beta_{2,22} & \beta_{2,23} \\
\beta_{2,31} & \beta_{2,32} & \beta_{2,33}
\end{array}\right] \times\left[\begin{array}{l}
X_{1 t-2} \\
X_{2 t-2} \\
X_{3 t-2}
\end{array}\right]+} \\
\cdots+\left[\begin{array}{lll}
\beta_{p, 11} & \beta_{K, 12} & \beta_{K, 13} \\
\beta_{K, 21} & \beta_{p, 22} & \beta_{K, 23} \\
\beta_{K, 31} & \beta_{K, 32} & \beta_{K, 33}
\end{array}\right] \times\left[\begin{array}{l}
X_{1 t-K} \\
X_{2 t-K} \\
X_{3 t-K}
\end{array}\right]+\left[\begin{array}{l}
\varepsilon_{1 t} \\
\varepsilon_{2 t} \\
\varepsilon_{3 t}
\end{array}\right]
\end{gathered}
$$

Variable $X_{\mathrm{it}}$ does not Granger cause variable $X_{\mathrm{jt}}$ if the following null hypothesis is not rejected: $H_{0}: \beta_{1, j i}=\beta_{2, j i}=\cdots=\beta_{K, j i}=0$. 
asymptotical chi-square distributions. For this reason we will make use of the bootstrap simulation techniques to generate our own critical values in causality tests. Another advantage of bootstrapping is that it is based on the empirical distribution of the data and it is not sensitive to normal distribution. As it is well known, the probability of extreme events in the financial markets is much higher than what the normal distribution would suggest (Chunchachinda, et al., 1997; Hatemi-J, 2002; Liu, et al., 2003; Poon, et. al., 2004; among others). Hence, more efficiency in the inference can be gained if the empirical distribution of the data (which does not have to be normally distributed) is used. This empirical distribution can be generated through bootstrap resampling techniques. Another aspect of financial data is that usually the volatility is time dependent (the presence of ARCH affects). In order to make sure that the presence of ARCH effects does not render biased results, we apply the leveraged bootstrap to be defined later.

The bootstrap causality test is performed in the following manner. First, Equation 5 is estimated with the null hypothesis of no Granger causality imposed. Then the bootstrapped value for the simulated data, $X^{*}$, is produced by the following equation:

$$
X^{*}=\hat{D} Z+\delta^{*}
$$

Where $\hat{D}$ is estimated as

$$
\hat{D}=X Z^{\prime}\left(Z Z^{\prime}\right)^{-1} \text {. }
$$

$\delta^{*}$ is the bootstrap residual terms, which are based on $T$ independent draws with replacement from the regression's modified residuals (to be defined shortly), each with equal probability of $1 / T$. The mean of the resulting set of drawn modified residuals is subtracted from each of the modified residuals in that set to make sure that the mean value of the bootstrap residual is equal to zero. The modified residuals are the raw residuals from regression (5), which are modified by leverages to have constant variance. ${ }^{6}$ To be explicit about leverage adjustments, we need to introduce some more notations. Let $X_{-K}=\left(X_{1-K}, \cdots, X_{T-K}\right)$ and let $X_{i,-K}, i=1$, 2 , or 3 be the $i$ th row of $X_{-K}$, i.e. it is a row vector of the lag $L$ values for variable $X_{i t}, t=1, \ldots$ , $T .^{7}$ Let also $Y=\left(X_{-1}{ }^{\prime}, \cdots, X_{-K}{ }^{\prime}\right)$ and $Y_{i}=\left(X_{i,-1}{ }^{\prime}, \cdots, X_{i,-K}{ }^{\prime}\right)$. For the equation that determines $X_{l t}$, the explanatory variable matrix for the regression is $Y_{l}$; this equation is restricted to have no Granger causality. For the equations that determine $X_{2 t}$, and $\mathrm{X}_{3 t}$ the

\footnotetext{
${ }^{6}$ This leverage adjustment was suggested by Davison and Hinckley (1999). Hacker and Hatemi-J (2005) generalised this adjustment to multivariate cases.

${ }^{7}$ Note that, $i=1,2,3$ because we have only three variables in our model.
} 
explanatory variable matrix for the regression is $Y$; this equation allows all lags of all three variables to be included. The $T \times 1$ leverages vectors for $X_{1 t}$, and $X_{2 t}, t=1, \ldots, T$ are respectively defined as

$$
\begin{aligned}
& h_{1}=\operatorname{diag}\left(Y_{1}\left(Y_{1}^{\prime} Y_{1}\right)^{-1} Y_{1}^{\prime}\right), \text { and } \\
& h_{2}=\operatorname{diag}\left(Y\left(Y^{\prime} Y\right)^{-1} Y^{\prime}\right)
\end{aligned}
$$

and

$$
h_{3}=\operatorname{diag}\left(Y\left(Y^{\prime} Y\right)^{-1} Y^{\prime}\right)
$$

Let $h_{i t}$ be the $t$ th element of $h_{i}$, and let $\widetilde{\varepsilon}_{i t}$ be the raw residual from the regression for $X_{i t}, i$ $=1,2,3$. The modified residual for $X_{i t}$ is defined as

$$
\widetilde{\varepsilon}_{i t}^{m}=\frac{\widetilde{\varepsilon}_{i t}}{\sqrt{1-h_{i t}}}
$$

We perform the bootstrap simulation 10000 times in order to produce the $W$ test statistic each time. By this way we can generate the empirical (bootstrap) distribution for the $W$ test statistic. Subsequent to these 10000 estimations we find the $(\alpha)$ th upper quantile of the distribution of bootstrapped $W$ statistics, which is the $\alpha$-level "bootstrap critical values" $\left(c_{\alpha}^{*}\right)$. Then, we calculate the $W$ statistic using our true data (not the bootstrapped simulated data) and we compare it with $c_{\alpha}^{*}$. The null hypothesis of no Granger causality is rejected based on bootstrapping if the actual $W$ test value is greater than the bootstrap critical value at the $\alpha$ level of significance, i.e. $c_{\alpha}^{*}$. We generate the bootstrap critical values for $1 \%, 5 \%$ and $10 \%$ significance levels. The leveraged bootstrap simulations are performed by a program procedure in GAUSS, which is available on request.

The extent of causality between the markets is then derived from the estimated parameters of the VAR model. The extent of causality from market $i$ to market $j$ is defined as the sum of the lagged coefficients in Equation 7: $\sum_{k=1}^{K} \beta_{k, j i}$. In the next sub-section we suggest an approach to 
calculate the bootstrap correlation coefficients that allows for causal interaction between the markets, which can to be used as inputs to construct international portfolios.

\section{$\underline{4.4 \text { Bootstrap Correlation Coefficients }}$}

We calculate bootstrap correlation coefficients for pair of markets based on the residuals of the VAR model. The bootstrap correlation coefficients therefore indirectly take into account the size of the causal effects and the dynamic structure between the underlying markets. We conduct the following steps in calculating the bootstrap correlation coefficients: ${ }^{8}$

1. Resample with replacement the residuals from the VAR model for Countries 1 and 2 $\left(\varepsilon_{1}\right.$ and $\left.\varepsilon_{2}\right)$ and denote them $\varepsilon_{1} *$ and $\varepsilon_{2}^{*}$, i.e.:

$\varepsilon_{1}^{*}=\left\{\varepsilon_{1} *^{1}, \varepsilon_{1} *^{2}, \ldots, \varepsilon_{1}^{* \mathrm{i}}\right\} \quad \varepsilon_{1} *^{\mathrm{i}} \in \varepsilon_{1} \forall i$. Where $i=1, \cdots, n$. and

where $\mathrm{n}$ is the bootstrap sample size.

$\varepsilon_{2}{ }^{*}=\left\{\varepsilon_{2}{ }^{1}, \varepsilon_{2} *^{2}, \ldots, \varepsilon_{2}{ }^{* \mathrm{i}}\right\} \quad \varepsilon_{2}{ }^{* \mathrm{i}} \in \varepsilon_{2} \forall i$. Where $i=1, \cdots, n$.

2. Calculate the correlation by using $\varepsilon_{1}^{*}$ and $\varepsilon_{2}^{*}$ and denote the $\rho *$ respectively.

$$
\rho^{*}=\frac{\sum \varepsilon_{1}^{*} \varepsilon_{2}^{*}-\frac{\sum \varepsilon_{1}^{*} \times \sum \varepsilon_{2}^{*}}{n}}{\sqrt{\frac{\sum \varepsilon_{1}^{*^{2}}}{n-2} \times \sqrt{\frac{\sum \varepsilon_{2}^{*^{2}}}{n-2}}}}
$$

3. Repeat steps one and two $N$ times.

4. Calculate the bootstrap correlation $\left(\rho_{B}\right)$.

$$
\rho_{B}=\frac{\sum_{j=1}^{N} \rho^{*}}{N} \text {, where } N \text { is the number of bootstrap iterations. }{ }^{9}
$$

\section{Estimation Results}

The optimal lag order based on minimization of equation (4) was chosen to be one. ${ }^{10}$ The residuals in the VAR(1) model was tested for normality and ARCH effects. Using Doornik and Hansen (1994) test, we found that the null hypothesis of multivariate normality could be

\footnotetext{
${ }^{8}$ The bootstrap correlation coefficient for other pairs of countries is estimated in a similar way.

${ }^{9}$ Our Gauss procedure to calculate the bootstrap correlations is available on request.

${ }^{10}$ It should be mentioned that the maximum lag length of up to twenty was considered. We tested also for multivariate autocorrelation by making use of a modified LM test suggested by Hatemi-J (2004).
} 
strongly rejected. We also tested for multivariate ARCH effects using the Hacker and Hatemi$\mathrm{J}$ (2005b) test. The results showed that the null hypothesis of no multivariate ARCH could be strongly rejected. Based on the simulation results provided by Hacker and Hatemi-J (2005) and Hatemi-J (2005), tests for causality perform badly if non-normality and ARCH effects exist. The authors suggest a bootstrap test with leverage adjustments to improve the inference under such circumstances.

The results for causality tests based on bootstrap simulation technique are presented in Table 2. The potential causality found was only from the US to the UK and Japan but this only occurs at the $10 \%$ level of significance. Furthermore, the size of the causal effects is almost negligible. We also checked the significance of the causality based on critical values derived from asymptotic distribution. These values are shown in parentheses in Table 2. Even if these values are different from the bootstrapped ones, the same results are obtained. Thus, the absence of significant level of causality between the three markets seems to be quite robust.

Table 2: Causality Test Results Based on Bootstrap Simulation Techniques.

\begin{tabular}{|c|c|c|c|c|c|}
\hline $\begin{array}{l}\text { The Null } \\
\text { Hypothesis }\end{array}$ & $\begin{array}{c}\text { The Estimated } \\
\text { Test Value }\end{array}$ & $\begin{array}{l}\text { 1\% Bootstrap } \\
\text { Critical Value }\end{array}$ & $\begin{array}{l}5 \% \text { Bootstrap } \\
\text { Critical Value }\end{array}$ & $\begin{array}{l}10 \% \text { Bootstrap } \\
\text { Critical Value }\end{array}$ & $\begin{array}{c}\text { The Size of } \\
\text { Causal Effect }\end{array}$ \\
\hline $\begin{array}{c}\mathrm{SP}_{\mathrm{US}} \neq> \\
\mathrm{SP}_{\mathrm{UK}}\end{array}$ & $3.193 *$ & $\begin{array}{l}6.809 \\
(6.63)\end{array}$ & $\begin{array}{l}4.072 \\
(3.84)\end{array}$ & $\begin{array}{l}2.761 \\
(2.71)\end{array}$ & 0.002 \\
\hline $\begin{array}{l}\mathrm{SP}_{\text {US }} \neq> \\
\mathrm{SP}_{\text {JAPAN }}\end{array}$ & $3.602 *$ & $\begin{array}{l}7.033 \\
(6.63)\end{array}$ & $\begin{array}{l}4.116 \\
(3.84)\end{array}$ & $\begin{array}{l}2.921 \\
(2.71)\end{array}$ & 0.003 \\
\hline $\begin{array}{c}\mathrm{SP}_{\mathrm{UK}} \neq> \\
\mathrm{SP}_{\mathrm{US}}\end{array}$ & 0.610 & $\begin{array}{l}7.816 \\
(6.63)\end{array}$ & $\begin{array}{l}4.071 \\
(3.84)\end{array}$ & $\begin{array}{l}4.839 \\
(2.71)\end{array}$ & -0.001 \\
\hline $\begin{array}{l}\mathrm{SP}_{\text {UK }} \neq> \\
\mathrm{SP}_{\text {JAPAN }}\end{array}$ & 0.005 & $\begin{array}{l}6.491 \\
(6.63) \\
\end{array}$ & $\begin{array}{l}3.749 \\
(3.84)\end{array}$ & $\begin{array}{l}2.409 \\
(2.71)\end{array}$ & -0.001 \\
\hline $\begin{array}{c}\mathrm{SP}_{\text {JAPAN }} \neq> \\
\text { SP }_{\text {US }}\end{array}$ & 1.990 & $\begin{array}{l}6.852 \\
(6.63) \\
\end{array}$ & $\begin{array}{l}3.909 \\
(3.84) \\
\end{array}$ & $\begin{array}{l}2.738 \\
(2.71) \\
\end{array}$ & 0.001 \\
\hline $\begin{array}{c}\text { SP }_{\text {JAPAN }} \neq> \\
\text { SP }_{\text {UK }}\end{array}$ & 0.187 & $\begin{array}{l}6.723 \\
(6.63)\end{array}$ & $\begin{array}{l}3.699 \\
(3.84)\end{array}$ & $\begin{array}{l}2.585 \\
(2.71)\end{array}$ & -0.002 \\
\hline
\end{tabular}

Notes:

1. The notation $\mathrm{A} \neq>\mathrm{B}$ indicates that $\mathrm{A}$ does not Granger cause $\mathrm{B}$.

2. The optimal lag order in the VAR model $(K)$ was set to two according to Hatemi-J information criterion (see equation 4).

3. The number of leveraged bootstrap simulations used to generate the critical values for each null hypothesis was 10000 .

4. Figures in parentheses indicate critical values based on asymptotic $\chi^{2}$ distribution with one degree of freedom.

5.* implies significance at the $10 \%$ level. 
We interpret these results as further empirical evidence that international diversification is still a profitable activity for investors in the global financial market. That is, the correlations that were used in traditional portfolio analysis can be considered reliable even in causal terms. Furthermore, although not the main purpose of the study, these results also confirm the existing view in relation to the interdependence among markets, that the US is dominant worldwide and the Japanese market, in spite of its size, is not able to match the influence of the US (see, for instance, Eun and Shim, 1989 and Darrat and Zhong, 2002).

Table 3 shows the bootstrap correlation coefficients that were obtained based on the procedures described in Section 4.4, which take into account the dynamic interaction (causality) that might exist between the underlying variables. As can be seen in this table, the bootstrap correlation coefficients are very similar to the standard correlations shown in Table 1. It could very well be the case that the correlations are the same because there is very negligible causality. Thus, it seems that the $46 \%$ potential benefits of international diversification are supported by the bootstrap causality test results and bootstrap correlations.

Table 3. Bootstrap Correlation Coefficients Matrix

\begin{tabular}{lccc}
\hline & US & Japan & UK \\
\hline US & 1 & $0.30039631^{* * *}$ & $0.45017666^{* * *}$ \\
Japan & $0.30039631^{* * *}$ & 1 & $0.33164356^{* * *}$ \\
UK & $0.45017666^{* * *}$ & $0.33164356^{* * *}$ & 1 \\
\hline$* * *$ implies that the null hypothesis of correlation coefficient being equal to 1 is rejected at the one percent \\
significance level in favour of the alternative hypothesis of correlation coefficient being less than 1.
\end{tabular}

\section{Conclusions}

This study examines whether international portfolio diversification can still result in gains in terms of an increase in risk-adjusted returns in an increasingly integrated global financial market. We apply two approaches, namely - the traditional portfolio analyses and the bootstrapped causality tests combined with bootstrap correlation coefficients, that we suggest, to account for the dynamic structure of the markets. Our results based on portfolio approach reveal that diversifying internationally between the world's three largest financial markets (the US, the UK and Japan) can increase risk-adjusted returns. The bootstrapped tests for causality show that there might exist causality from at least one variable to the others in the portfolio. However, the causal effect seems to be negligible. Furthermore, the bootstrap correlation coefficients were about the same size as the standard correlations. This provides 
additional empirical support for the view that international diversification can still provide gains to investors. In this study, we have still contributed in terms of providing a framework for future studies on the issue of international portfolio diversification. As stated earlier in the introduction, this study can be expanded in a number of ways such as increasing the number of markets, taking into account the point of view of investors from the different markets, and analysing the effect of exchange rates on the size of the diversification benefits in line, for instance, with the studies of Eun and Resnick (1988) and Jorion (1985).

\section{Acknowledgements}

We would like to express our thanks to the Editor of this journal and the anonymous referee for their important comments that resulted in a major improvement of this paper through several revisions. An earlier version of this paper was also presented at the 2003 Econometric Society Meeting, which was held in Sydney, Australia. We like to thank the participants for their useful comments. The usual disclaimer applies.

\section{References}

Bertero, E. and C. Mayer (1990) "Structure and Performance: Global Interdependence of Stock Markets and the Crash of October 1987", European Economic Review, 34, pp. 1155-1180.

Chunchachinda, P.; K. Dandapani; S. Hamid and A.J. Prakash (1997) "Portfolio Selection and Skewness: Evidence from International Stock Markets", Journal of Banking and Finance, 21, pp. 143-167.

Doornik, J. A., and Hansen, H., 1994, “An Omnibus Test for Univariate and Multivariate Normality”, Working paper, Nuffield College, Oxford University, Oxford, UK.

Darrat, A.F. and M. Zhong (2002) "Permanent and Transitory Driving Forces in the AsianPacific Stock Markets", The Financial Review. Vol. 37 (1). p 35-51.

Davison, A. C., and Hinkley, D.V. (1999) Bootstrap Methods and Their Application. Cambridge University Press. Cambridge, UK.

Efron, B. (1979) Bootstrap Methods: Another Look at the Jackknife, Annals of Statistics 7, 126.

Elton, E.J. and M.J. Gruber (1995) Modern Portfolio Theory, $5^{\text {th }}$ ed., John Wiley \& Sons.

Erb, C.B.; C.R. Harvey and T.E. Viskanta (1994) "Forecasting International Equity Correlations", Financial Analysts Journal, 50, pp. 32-45. 
Eun, C. and B. Resnick (1994) "International Diversification of Investment Portfolios: US and Japanese Perspective”, Management Science, 40, pp. 140-161.

Eun, C. and S. Shim (1989) "International Transmission of Stock Market Movements", Journal of Financial and Quantitative Analysis, 24, 2, pp. 241-256.

Eun, C. and B. Resnick (1988) "Exchange Rate Uncertainty, Forward Contracts and International Portfolio Selection", Journal of Finance, 43, pp. 197-215.

Granger, C. W. J, (1969) 'Investigating Causal Relations by Econometric Models and Cross Spectral Methods", Econometrica, 37, 424-438.

Grubel, H.G. (1968) "Internationally Diversified Portfolios: Welfare Gains and Capital Flows", American Economic Review, 58, pp. 1299-1314.

Haavisto, T. and B. Hansson (1992) "Risk Reduction by Diversification in the Nordic Stock Markets”, Scandinavian Journal of Economics, 94, 4, pp. 581-588.

Hacker R. S. and Hatemi-J, A. (2005) "Tests for Causality between Integrated Variables Using Asymptotic and Bootstrap Distributions: Theory and Application" Applied Economics, forthcoming.

Hacker R. S. and Hatemi-J, A. (2005b) "A Test for Multivariate ARCH Effects" Applied Economics Letters, 12, 7, pp. 411-417.

Hanna, M.E.; J.P. McCormack and G. Perdue (1999) “A Nineties Perspective on International Diversification", Financial Services Review, 8, pp. 37-45.

Hatemi-J, A. (2002) "Money Supply and the Informational Efficiency of the Stock Market in Korea : Evidence from an Alternative Methodology". Journal of Economic Integration, 17,3 , pp. 517-526.

Hatemi-J, A. (2003) “A New Method to Choose Optimal Lag Order in Stable and Unstable VAR Models". Applied Economics Letters, 10, 3, pp. 135-137.

Hatemi-J, A. (2004) "Multivariate Tests for Autocorrelation in the Stable and Unstable VAR Models”. Economic Modelling, 21, 4, pp.661-683.

Hatemi-J, A. (2005) "A Bootstrap Corrected Test for Causality: Theory and Applications in Finance", Invited Key-speaker Presentation at II SIMPOSIO NACIONAL DE DOCENTES EN FINANZAS, July 13-15, 2005, Bogota.

Hatemi-J, A. and Roca E. (2004) "An examination of the equity market price linkage between Australia and the European Union using leveraged bootstrap method". European Journal of Finance, 10, 6, pp.475-488.

Jorion, P. (1985) “International Diversification with Estimation Risk", Journal of Business, July, pp. 259-278. 
Kaplanis, E.C. (1988) "Stability and Forecasting of the Co-Movement Measures of International Stock Market Returns", Journal of International Money and Finance, 7, pp. 63-75.

King, M.A. and S.B. Wadwhani (1990) “Transmission of Volatility Between Stock Markets”, Review of Financial Studies, 3, pp. 5-33.

Koch, P.D. and T.W. Koch (1991) "Evolution in Dynamic Linkages Across National Stock Indexes", Journal of International Money and Finance, 10, pp. 231-251.

Lee, S.B. and K.J. Kim (1993) "Does the October 1987 Crash Strengthen the Co-Movements among National Stock Markets”, Review of Financial Economics, 3, pp. 89-102.

Levy, H. and M. Sarnat (1970) "International Diversification of Investment Portfolios", American Economic Review, 60, pp. 668-675.

Liljeblom, E.; A. Loflund and S. Krokfors (1997) "The Benefits from International Diversication for Nordic Investors", Journal of Banking and Finance, 21, pp. 469-490.

Liu, J.; F.A. Longstaff, and J. Pan (2003). "Dynamic Asset Allocation with Event Risk", Journal of Finance, 58, pp. 231-259.

Longin, F. and B. Solnik (1995) "Is the Correlation of International Equity Returns Constant: 1960-1990", Journal of International Money and Finance, 14, pp. 3-26.

Longin, F. and B. Solnik (2001). "Extreme Correlation of International Equity Markets", Journal of Finance, 56, pp. 649-676.

Merton, R.C. (1972) “An analytic Derivation of the Efficient Frontier”, Journal of Financial and Quantitative Analysis, September, pp. 1851-1872.

Panton, D.B.; V.P. Lessig and O.M. Joy (1976) "Co-Movement of International Equity Markets: A Taxonomic Approach”, Journal of Financial and Quantitative Analysis, 11, 3, pp. 415-432.

Poon, S.; M. Rockinger, and J. Tawn (2004). "Extreme Value Dependence in Financial Markets: Diagnostics, Models, and Financial Implications", The Review of Financial Studies, 17, 2, pp. 581-610.

Ratner, M. (1992) "Portfolio Diversification and the Inter-Temporal Stability of International Indices", Global Finance Journal, 3, pp. 67-68.

Roca, E. (1999) "Short-Term and Long-Term Price Linkages between the Equity Markets of Australia and Its Major Trading Partners", Applied Financial Economics, 9, 501-11.

Shawky, H.A.; R. Kuenzel and A.D. Mikhail (1997) "International Portfolio Diversification: A Synthesis and An Update", Journal of International Financial Markets, Institutions and Money, 7, pp. 303-327. 
Sharpe, W. (1966) "Mutual Fund Performance”, Journal of Business, A Supplement, I, Part 2, pp. 119-138.

Sims, C. A., Stock, J. H., and Watson. M. W. (1990) "Inference in Linear Time Series Models with Some Unit Roots". Econometrica, 58, 133-44.

Solnik, B.(1973) European Capital Markets. Lexington, MA: Lexington Books.

Solnik, B. (1974) “Why Not Diversify Internationally Rather Than Domestically?”, Financial Analysts Journal, July-August.

Solnik, B. (1993) "The Performance of International Allocation Strategies Using Conditioning Information", Journal of Empirical Finance, 1, pp. 33-55.

Tobin, J. (1958) "Liquidity Preference As Behaviour Towards Risk", Review of Economic Studies, 26, pp. 65-86.

Toda, H. Y. and Yamamoto, T. (1995) Statistical Inference in Vector Autoregressions with Possibly Integrated Processes. Journal of Econometrics, 66, 225-250.

Von Furstenberg, G.M. and B.N Jeon (1989) "International Stock Prices Movements: Links and Messages", Brookings papers on Economic Activity, 1, pp. 125-179. 